Viktor J. Vanberg

\title{
Wettbewerb und Regelordnung
}

\author{
Hrsg. v. Nils Goldschmidt u. Michael Wohlgemuth. Mit einer Einf. v. Hans Albert
}

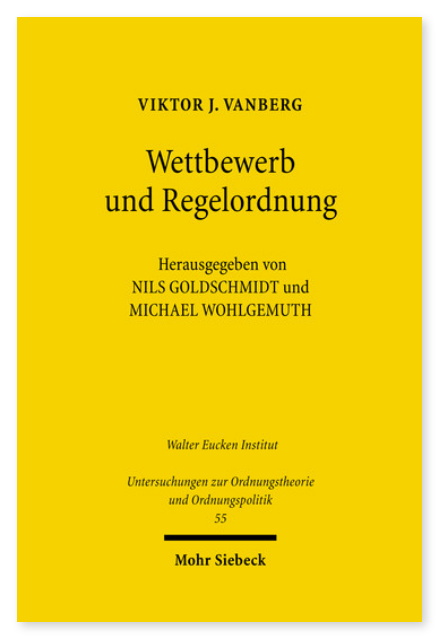

2008; unveränderte Studienausgabe; 2009. VIII, 328 Seiten. UOrd 55

ISBN 978-3-16-151480-7

DOI 10.1628/978-3-16-151480-7

eBook PDF $69,00 €$

ISBN 978-3-16-150074-9

fadengeheftete Broschur 69,00€
»Wettbewerb und Regelordnung « sind die beiden Kernelemente des Forschungsprogramms von Viktor J. Vanberg. Er steht hiermit in einer langen Tradition ausgehend von der Schottischen Moralphilosophie, über die Freiburger Ordnungsökonomik, hin zur Sozialtheorie von Friedrich August von Hayek und zur Verfassungsökonomik von James Buchanan. In der jetzt vorliegenden Studienausgabe widmet Vanberg all diesen Forschungstraditionen seine Aufmerksamkeit, ohne sich mit ideengeschichtlichen Einordnungen zufrieden zu geben. Durch sorgfältige Korrekturen und umsichtige Synthesen gelingt es Vanberg, diese Stränge konsistent zusammenzuführen und weiter zu entwickeln.

Die in diesem Band zusammengeführten Arbeiten weisen Vanberg als einen der Hauptvertreter moderner Ordnungsökonomik und als entscheidenden Wegbereiter der Verfassungsökonomik aus. Dabei erfahren die Marktordnung und der demokratische Rechtsstaat jeweils auf Grundlage eines privilegienfreien Leistungswettbewerbs zugunsten souveräner Bürger eine anspruchsvolle normative Begründung. Gleichzeitig zeigen Vanbergs Beiträge zu den methodologischen und verhaltenstheoretischen Grundlagen der Wirtschafts- und Sozialwissenschaften welche grundlegenden Erkenntnisfortschritte erst dann möglich werden, wenn Ökonomik als erfahrungswissenschaftlich orientierte "Lebenswissenschaft« und nicht als schlichte Gleichgewichtsmechanik oder Maximierungslogik angelegt ist. Mit diesen Überlegungen knüpft Vanberg an Hans Alberts Kritik des ökonomischen »Modell-Platonismus« an.«

Aus dem Vorwort von Nils Goldschmidt und Michael Wohlgemuth

Inhaltsübersicht

Hans Albert: Viktor Vanberg und das sozialwissenschaftliche Erkenntnisprogramm I. Die ordnungsökonomische Perspektive

Der konsensorientierte Ansatz der konstitutionellen Ökonomik - Die normativen Grundlagen von Ordnungspolitik II. Wirtschaftsverfassung und Staatsverfassung

Privatrechtsgesellschaft und Ökonomische Theorie - Die Verfassung der Freiheit: Zum Verhältnis von Liberalismus und Demokratie - Bürgersouveränität und wettbewerblicher Föderalismus: Das Beispiel der EU

III. Das Paradoxon der Marktwirtschaft

Das Paradoxon der Marktwirtschaft:Die Verfassung des Marktes und das Problem der »sozialen Sicherheit« - Soziale Sicherheit, Müller-Armacks »Soziale Irenik« und die ordoliberale Perspektive - Ordnungsökonomik und Ethik - Zur Interessenbegründung von Moral IV. Wahrnehmung, Evolution und Marktprozess

Rationalitätsprinzip und Rationalitätshypothesen: Zum methodologischen Status der Theorie rationalen Handelns Rationalität, Regelbefolgung und Emotionen: Zur Ökonomik moralischer Präferenzen - Der Markt als kreativer Prozess (mit James M. Buchanan ) - Die Ökonomik ist keine zweite Physik

Viktor J. Vanberg 1995-2009 Professor für Wirtschaftspolitik an der Universität Freiburg; 2001-10 Leiter des Walter Eucken Instituts Freiburg; seit 2010 Senior Research Fellow und Vorstand, Walter Eucken Institut. https://orcid.org/0000-0002-2200-8260

Nils Goldschmidt ist Professor für Kontextuale Ökonomik und ökonomische Bildung an der Universität Siegen.

Michael Wohlgemuth Geboren 1965; Studium der Volkswirtschaftslehre; 1999 Promotion; 2007 Habilitation; u.a. apl. Professor an der Universität Witten / Herdecke und Forschungsbeauftragter der Stiftung für Staatsrecht und Ordnungspolitik, Liechtenstein.

Jetzt bestellen:

https://mohrsiebeck.com/buch/wettbewerb-und-regelordnung-9783161514807?no_cache=1

order@mohrsiebeck.com

Telefon: +49 (0)7071-923-17

Telefax: +49 (0)7071-51104 